\title{
Inelastic electron tunneling spectroscopy in molecular junctions showing quantum interference
}

\author{
C. Salhani, M. L. Della Rocca, ${ }^{*}$ C. Bessis, R. Bonnet, C. Barraud, and P. Lafarge \\ Université Paris Diderot, Sorbonne Paris Cité, MPQ, UMR 7162, CNRS, 10 rue A. Domon et L. Duquet, \\ 75205 Paris Cedex 13, France
}

\author{
A. Chevillot, P. Martin, and J.-C. Lacroix \\ Université Paris Diderot, Sorbonne Paris Cité, ITODYS, UMR 7086, CNRS, 15 rue J.-A. de Baïf, 75205 Paris Cedex 13, France \\ (Received 6 February 2017; revised manuscript received 31 March 2017; published 19 April 2017)
}

\begin{abstract}
Destructive quantum interference effect is implemented in large area molecular junctions to improve signatures of electron-phonon interaction. Vertical molecular junctions based on a cross-conjugated anthraquinone layer were fabricated and low-noise transport measurements were performed by acquiring simultaneously the current-voltage characteristics, its second derivative, and the differential conductance. Signatures of vibrational modes excited by inelastic events are present in the whole measured voltage range and superpose to the conductance suppression induced by destructive quantum interference. As a consequence vibrational modes have improved visibility in the low energy window $(<80 \mathrm{meV})$. Inelastic electron transport spectroscopy data are compared to infrared attenuated total reflection spectroscopy on Au/anthraquinone thin films. Common vibrational modes can be clearly identified, but inelastic electron tunneling spectroscopy reveals the existence of vibrational modes in a wider energy range $(0-400 \mathrm{meV})$ where infrared spectroscopy is lacking.
\end{abstract}

DOI: 10.1103/PhysRevB.95.165431

\section{INTRODUCTION}

Quantum interference (QI) between different molecular orbital pathways has recently emerged as a new route for controlling electronic transport in molecular devices [1-7]. This quantum mechanical effect arises from simultaneous and opposite contributions to coherent charge transport of at least two molecular orbitals and induces a strong antiresonance in the energy dependent transmission function at the single molecule scale. Quantum interference takes place in molecules where the $\pi$-electron system is cross-conjugated such as anthraquinone (AQ) and results in a strong suppression of conductance with respect to more conducting linearly conjugated molecules [1-7]. The resulting suppression of conductance has been reported experimentally using different techniques such as conducting atomic force microscopy [8], eutectic GaIn contact [9], mechanically controllable break junctions [10], and large-area molecular junctions [11]. The AQ molecule, due to its intrinsic cross-conjugated structure, has been used in most of these experimental works under the form of a single molecule and thin films [8,9,11]. The use of QI as a means of controlling charge transport through molecules is envisioned in many applications, such as quantum interference effect transistor [1,2], logic gates [3], and nanodevices for energy conversion and harvesting $[12,13]$. In this context, in situ investigations of the interplay between QI and electron-phonon (el-ph) interaction at work in cross-conjugated molecules are highly desirable. Here, we have realized inelastic electron tunneling spectroscopy (IETS) of a thin anthraquinone layer embedded between two metallic electrodes in a vertical junction configuration. For single molecule devices weakly coupled to the electrodes, spectroscopy of vibrational modes as a function of gate voltage has been reported in the Coulomb blockade regime

\footnotetext{
*maria-luisa.della-rocca@univ-paris-diderot.fr
}

[14-19]. However, for the case of molecules strongly coupled to the leads, such as in the quantum interference regime, IETS remains a better spectroscopic tool [20-27]. Recent theoretical works have calculated the inelastic contributions to the current in the presence of QI [28] and have explored propensity rules that can play a role in this case [29,30]. QI is not completely quenched by the decoherence due to the inelastic interaction of electrons with molecular vibrational modes; furthermore, the inelastic contributions to the current in the presence of QI is predicted to be larger than in molecules without interference meaning that QI can be exploited to investigate vibrational mode signatures on electronic transport. In the following, we present IETS measurements of AQ layers in a bias voltage range within which destructive quantum interference suppresses elastic charge transport. The results are consistent with those obtained by infrared attenuated total reflection spectroscopy (ATR) on Au/AQ grafted layers. IETS reveals features in a wider energy interval with respect to IR spectroscopy and with enhanced visibility in the low energy range. In particular, transport spectroscopy shows up many IR inactive nitrogen based vibrations.

\section{SAMPLE FABRICATION AND METHODS}

Molecular junctions are fabricated by conventional cleanroom microfabrication techniques in a cross-bar geometry $[11,31]$. Starting from a $\mathrm{Si} / \mathrm{SiO}_{2}$ substrate, the bottom electrode is first fabricated by optical lithography and $e$-beam evaporation $\left(10^{-8} \mathrm{mbar}\right)$. It consists in a $15 \mathrm{~mm}$ long, $20 \mu \mathrm{m}$ wide metallic stripe made of Ti/Au $(2 \mathrm{~nm} / 50 \mathrm{~nm})$. The stripe geometry is optimized for the successive electrochemical grafting procedure of the molecular layer by electroreduction of diazonium salts [31]. The latter is performed by cyclic voltammetry (scan rate of $100 \mathrm{mV} / \mathrm{s}$; potential range $-0.3 \mathrm{~V}<\mathrm{V}<0.4 \mathrm{~V}$ ) inducing the electroreduction of 9,10dioxo-1-anthracenediazonium salt in $\mathrm{C}_{2} \mathrm{H}_{3} \mathrm{~N}-\mathrm{NBu}_{4} \mathrm{BF}_{4}$ solution. Details on the electrografting procedure and molecular 
(a)
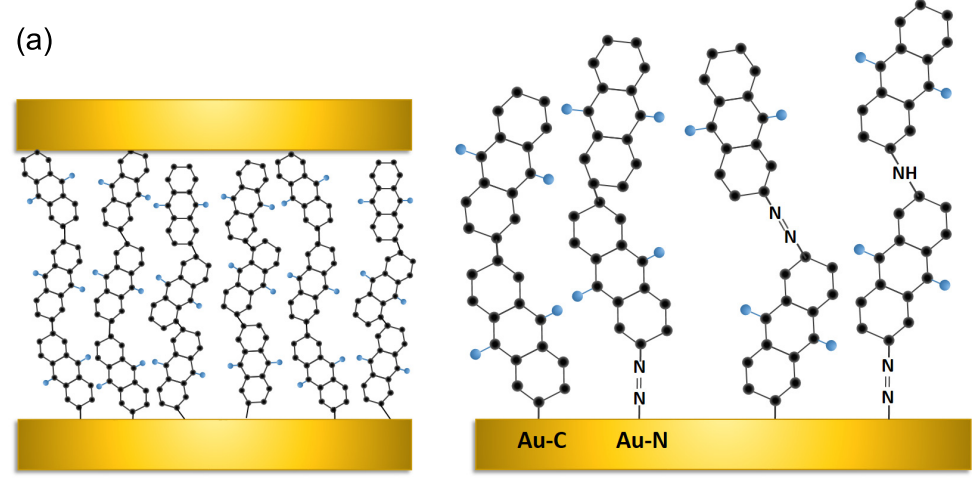

(b)

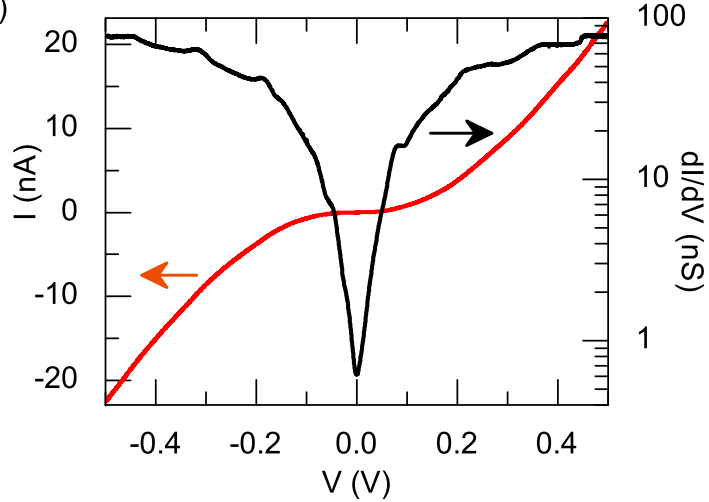

(c)

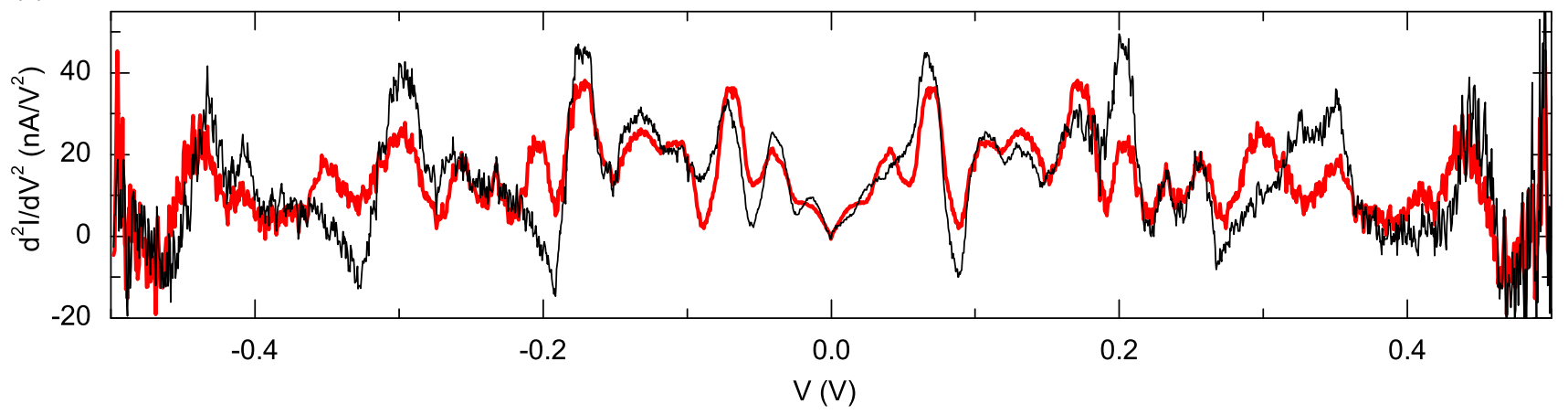

FIG. 1. (a) Simplified picture of the AQ based molecular junction and scheme of the possible covalent bonds (Au-C and Au-N) between the molecular layer and the base electrode induced by electrografting together with azo-based molecule-molecule bonds in the layer revealed by transport measurements. (b) Current-voltage characteristics $I(V)$ (red) and differential conductance $G(V)$ (black) as a function of voltage in an AQ based junction measured at $5 \mathrm{~K}$. The junction area is $\sim 20 \times 100 \mu \mathrm{m}^{2}$ and the molecular layer thickness is $\sim 8 \mathrm{~nm}$. (c) Measurement of the second derivative of the current $d^{2} I / d V^{2}$ as function of the voltage $V$ for the same junction at $5 \mathrm{~K}$ (black curve). The same data after symmetrization is superposed (red curve).

layer characterization are given in Refs. [11] and [31]. Redox grafting parameters, such as scan rate, switching potentials, and number of cycles, are chosen accordingly to Ref. [32] in order to obtain a thin molecular layer $(\sim 1-10 \mathrm{~nm})$ even for high number of cycles $(\mathrm{N}>10)$. This method ensures the formation of a robust and thin layer of $\mathrm{AQ}$ molecules bonded covalently to the electrode [32-35]. In the present case, for 20 voltammetry cycles the total AQ thickness is estimated by atomic force microscopy (AFM) to be $\sim 8 \mathrm{~nm}$. An AQ layer thickness of $\sim 8 \mathrm{~nm}$ means the formation of chains containing at least eight units of AQ molecules. It is consistent with the measured AQ surface concentration estimated by charge integration under the cyclic voltammetry peaks. The junction is finally completed by the evaporation of the counterelectrode in a cross-bar geometry. The top electrode is made of a Ti/Au bilayer $(2 \mathrm{~nm} / 50 \mathrm{~nm})$. A slow evaporation rate $(0.01 \mathrm{~nm} / \mathrm{s})$ through a shadow mask on the freshly deposited molecular layer is performed under the same conditions as for the base electrode $\left(10^{-8}\right.$ mbar $)$. This avoids the formation of pinholes through the junction. As opposite to the bottom electrode where covalentlike bonds are expected after electrografting, at the molecules/metal top electrode interface van der Waals interactions are mostly likely to occur. Anyway covalentlike bonds cannot be excluded. The junction area is $20 \times 100 \mu \mathrm{m}^{2}$. Figure 1 (a) shows a simplified picture of the AQ based molecular junction and a scheme of the possible bonds formed between the molecules and the base electrode together with the molecule/molecule bonds. Transport measurements are realized by measuring simultaneously the current-voltage characteristics $I(V)$, the differential conductance $G(V)$, and the second derivative of the current with respect to the voltage $d^{2} I / d V^{2}(V)$. We use a two-probes measurement setup, since the junction resistance is always much higher than the characteristic impedance of the connection lines $(50 \Omega)$. A low noise current amplifier is used to collect the ac and dc components of the current passing through the junction. Standard homodyne detection is used to measure the first and second harmonic response of the system to the ac modulation. The rms modulation voltage chosen for measurements is equal to $8 \mathrm{mV}$. This choice is a trade-off between a valuable detection and an adequate measurement averaging time as higher noise levels are associated to shorter measurement time. Transport measurements are performed in a variable temperature insert at $5 \mathrm{~K}$.

Infrared spectroscopy is performed on $\mathrm{Ti} / \mathrm{Au}$ surfaces functionalized by thin AQ molecular layers. Simultaneous to the junction base electrode evaporation, a Ti/Au bilayer is deposited on $\mathrm{Si} / \mathrm{SiO}_{2}$ substrates with typical dimensions of $10 \times 10 \mathrm{~mm}^{2}$. This surface is then functionalized following exactly the same electrochemical grafting procedure used for the molecular junction. The same number of grafting cycles has been used in order to obtain a molecular thickness identical to the one used in junctions. A Nicolet(C) spectrometer equipped with a standard MCT (Mercuric 

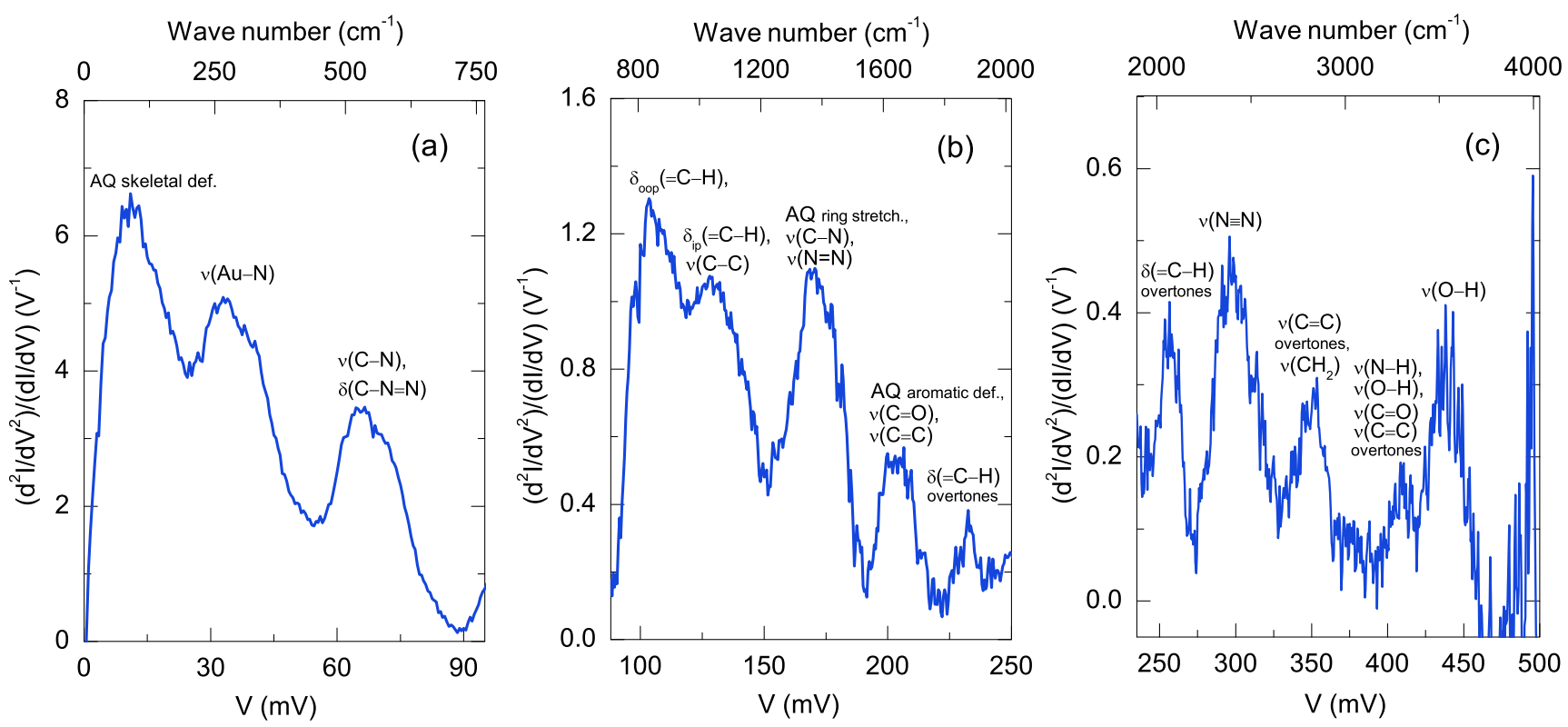

FIG. 2. Normalized second derivative of the current $\left(d^{2} I / d V^{2}\right) /(d I / d V)$ as a function of the voltage $V$ in the low (a), intermediate (b), and high (c) voltage ranges. The $x$ axis shows the energy dependence while the upper horizontal axis the wave number dependence.

Cadmium Telluride) detector with a resolution of the order of $4 \mathrm{~cm}^{-1}$ has been used. Spectra are acquired in an Ar purified atmosphere by attenuated total reflection (ATR) configuration. The ATR method is implemented with a standard Ge crystal and it is preferred for the investigation of the molecular layer being particularly adapted to probe thin film properties.

\section{AQ JUNCTIONS TRANSPORT MEASUREMENTS}

Figure 1(b) shows typical measurements of the currentvoltage characteristics of a junction (red curve) at $5 \mathrm{~K}$ together with the differential conductance (black curve) in the energy range $-0.5 \mathrm{~V}<\mathrm{V}<0.5 \mathrm{~V}$.

The $I(V)$ characteristic is highly nonlinear and the conductance measurement $G(V)$ shows a strong suppression over two orders of magnitude at zero bias. The conductance "dip" strongly suggests that destructive quantum interference is occurring in the large area device, in agreement with previously reported results on similar devices [11,36]. Clear conductance steps also appear in the explored voltage range. Figure 1(c) shows the measured $d^{2} I / d V^{2}(V)$ spectra acquired with a rms ac voltage of $8 \mathrm{mV}$, with frequency of $17 \mathrm{~Hz}$ and an integration time of $3 \mathrm{~s}$. The black line corresponds to the raw data in the whole explored voltage range. For negative polarity the sign of the $d^{2} I / d V^{2}$ has been inverted for the sake of clarity. The red line corresponds to data after symmetrization following the simple formula $y=[f(x)-f(-x)] / 2$, and revealing the existence of symmetric peaks $[21,37,38]$. Note that peak symmetry is less evident at higher energies. In that case, nonlinear process (field activated process, excitation of virtual states) can become dominant and may increase the noise level and reduce the symmetry in transport characteristics. Moreover, at higher energy different bias dependent tunneling paths can contribute to transport and reduce the symmetry of the spectrum $[49,64]$.
Figure 2 shows the symmetrized second derivative of the current as function of the voltage in the usual normalized representation $\left(d^{2} I / d V^{2}\right) /(d I / d V)$ in the low (a), intermediate (b), and high (c) explored voltage ranges. The $x$ axis shows the energy dependence, while the upper horizontal axis shows the wave number dependence. The second derivative measurement reveals peaks when new transport channels are activated corresponding to the inelastic excitation of phonon modes. Peak assignment is also indicated in Fig. 2 and discussed hereafter. In the low voltage region [Fig. 2(a)], the normalized $\left(d^{2} I / d V^{2}\right) /(d I / d V)$ amplitude is more intense than what is usually achieved by IETS with local probes [20-23] and in tunnel junctions [39-41], where typical peak intensities are at best of the order of $1-3 \mathrm{~V}^{-1}$. In the present case amplitudes higher than $5 \mathrm{~V}^{-1}$ have been achieved in the low voltage range, where the conductance suppression occurs. This reveals the ability to improve the visibility of the el-ph interaction in molecular layer in the presence of destructive quantum interference.

We now focus on the vibrational peak assignment of IETS spectra as shown on Fig. 2, realized by comparison to existing vibrational spectroscopy studies in literature [21,34,35,42-53]. Typical signatures of expected modes related to bonds of the AQ molecule are present in the whole energy range. AQ ring stretchings and ring deformations are probably related to the peak centered at $170 \mathrm{meV}\left(1370 \mathrm{~cm}^{-1}\right)$ $[42,43]$ and $203 \mathrm{meV}\left(1640 \mathrm{~cm}^{-1}\right)$, respectively [42]. Furthermore, the peak around $10 \mathrm{meV}\left(80 \mathrm{~cm}^{-1}\right)$ can be attributed to AQ skeletal deformation $[43,44]$. Note, however, that resonances in the low energy range usually involve metal/metal bonds as in the case of tip-apex metal vibrational modes measured in STM [45] and MBJ [47] based experiments. More generally, we recognize signatures that can be related to typical $\mathrm{CC}, \mathrm{CN}, \mathrm{CH}$, and $\mathrm{CO}$ bonds. The complex structure of the molecular thin film, however, is such that an exclusive peak assignment is not always possible. Aromatic $=\mathrm{C}-\mathrm{H}$ 
out-of-plane and in-plane deformations can be associated to the peaks around $104 \mathrm{meV}\left(839 \mathrm{~cm}^{-1}\right)[35,42,46]$ and $130 \mathrm{meV}$ $\left(1050 \mathrm{~cm}^{-1}\right)$ [34,35,42,43,46-48], respectively. Signatures of $\mathrm{C}=\mathrm{O}$ or $\mathrm{C}=\mathrm{C}$ stretching are identified in the peak centered at $205 \mathrm{meV}\left(1650 \mathrm{~cm}^{-1}\right)[21,35,47,48]$. Different nitrogen based bridge vibrations can also be assigned. Stretching modes of the $\mathrm{C}-\mathrm{N}$ bond are attributable to the low energy peak around $66 \mathrm{meV}\left(530 \mathrm{~cm}^{-1}\right)$, as well as at higher energy, around $170 \mathrm{meV}\left(1370 \mathrm{~cm}^{-1}\right)$ [42]. In this last case an azo-bridge stretching $\mathrm{N}=\mathrm{N}$ has been also reported [50] and at $66 \mathrm{meV}$ $\left(530 \mathrm{~cm}^{-1}\right)$ deformation of the $\mathrm{C}-\mathrm{N}=\mathrm{N}$ bond is also expected [42]. Furthermore, stretching of the $\mathrm{N}-\mathrm{H}$ can produce the band at $410 \mathrm{meV}\left(3300 \mathrm{~cm}^{-1}\right)$ [42] and the stretching of the $\mathrm{N} \equiv \mathrm{N}$ bond can be recognized in the peak around $297 \mathrm{meV}$ $\left(2400 \mathrm{~cm}^{-1}\right)[34,42,48]$. Note that azo-bonds are remarkably evident in our IETS measurements, while they are typically difficult to identify by infrared spectroscopy since they do not respond to characteristic selection rules, being symmetric in nature and thus inactive in IR. Moreover, the detection of azobased bonds vibrations reveals new insights on the structure of the molecular layer forming the junction. The electroreduction of the 9,10-dioxo-1-anthracenediazonium precursor results probably in molecular chains containing N-based bonds, such as $\mathrm{N}=\mathrm{N}, \mathrm{N}-\mathrm{H}$, and $\mathrm{C}-\mathrm{N}$, as schematically indicated in Fig. 1(a). Different bands in Fig. 2 might be attributed to overtones, which are predicted to be dominant spectroscopic features in molecular junction where quantum interference occurs [30]. Overtones of the $=\mathrm{C}-\mathrm{H}$ deformation can be related to the band arounds $235 \mathrm{meV}\left(1880 \mathrm{~cm}^{-1}\right)$ and $250 \mathrm{meV}\left(2100 \mathrm{~cm}^{-1}\right)$. Overtones related to the $\mathrm{C}=\mathrm{C}$ and $\mathrm{C}=\mathrm{O}$ stretching are probably present at $350 \mathrm{meV}\left(2820 \mathrm{~cm}^{-1}\right)$ and $410 \mathrm{meV}\left(3300 \mathrm{~cm}^{-1}\right)$. Surprisingly, no clear signature of the expected covalent $\mathrm{Au}-\mathrm{C}$ bond is observed. The stretching of the Au-C bond has been measured around $50 \mathrm{meV}\left(415-430 \mathrm{~cm}^{-1}\right)$ in aryl diazonium salts functionalized gold nanoparticles and gold nanorods by high resolution energy loss spectroscopy and surface enhanced Raman spectroscopy, respectively [34,35]. Although IETS reveals low energy modes at $10 \mathrm{meV}\left(80 \mathrm{~cm}^{-1}\right)$ and $34 \mathrm{meV}$ $\left(275 \mathrm{~cm}^{-1}\right)$, as visible in Fig. 2(a), those peaks cannot be ascribed directly to the Au-C stretching. Rather we stress that the $\mathrm{Au}-\mathrm{N}$ stretching vibration is much more coherent with our experimental spectra, since it is expected around $35 \mathrm{meV}\left(280 \mathrm{~cm}^{-1}\right)[51,52,54]$. This observation allows us to speculate that given the position of the $\mathrm{N}^{2+}$ group in the 9,10-dioxo-1-anthracenediazonium, steric hindrance probably prevents the formation of direct $\mathrm{Au}-\mathrm{C}$ bonds and longer $\mathrm{Au}-\mathrm{N}=\mathrm{N}$ bonds are indeed formed to connect the molecules on the metallic surface. The structure of the $\mathrm{Au}-\mathrm{N}$ covalent bond most probably formed by electrografting is indicated in Fig. 1(a). We can conclude that the AQ molecular bonding to the base electrode can be a mixture of $\mathrm{Au}-\mathrm{N}$ and $\mathrm{Au}-\mathrm{C}$ bonds, as proposed in the scheme of Fig. 1(a).

Note finally that some peaks can be also attributed to residual traces of organic solvents, such as a $\mathrm{C}-\mathrm{C}$ stretching vibration at $130 \mathrm{meV}\left(1050 \mathrm{~cm}^{-1}\right)[34,35,42,47,48]$, a $\mathrm{CH}_{2}$ stretching at 345-360 meV (2780-2900 $\left.\mathrm{cm}^{-1}\right)$. Hydroxyl $\mathrm{O}-\mathrm{H}$ group bands are attributable to the peaks at $410 \mathrm{meV}$ $\left(3300 \mathrm{~cm}^{-1}\right)$ and $437 \mathrm{meV}\left(3525 \mathrm{~cm}^{-1}\right)$ and can be also related to vibrations of water molecules [42]. These large bands could also be associated to traces of hydroquinone, i.e., the reduced
TABLE I. Assignment of main vibrational modes identified in Fig. 2 by IETS spectroscopy.

\begin{tabular}{lcc}
\hline \hline $\begin{array}{l}\text { Energy } \\
(\mathrm{meV})\end{array}$ & $\begin{array}{c}\text { Wave number } \\
\left(\mathrm{cm}^{-1}\right)\end{array}$ & Assignment \\
\hline $6-18$ & $48-145$ & AQ skeletal def. \\
$25-40$ & $200-322$ & $v(\mathrm{Au}-\mathrm{N})$ \\
$60-75$ & $484-605$ & $v(\mathrm{C}-\mathrm{N})$ \\
& & $\delta(\mathrm{C}-\mathrm{N}=\mathrm{N})$ \\
$100-110$ & $800-890$ & $\delta_{\text {oop }}(=\mathrm{C}-\mathrm{H})$ \\
& & $\delta(\mathrm{N}-\mathrm{H})$ \\
$125-135$ & $1000-1090$ & $\delta_{i p}(=\mathrm{C}-\mathrm{H})$ \\
& & $v(\mathrm{C}-\mathrm{C})$ \\
$165-180$ & $1330-1450$ & $\mathrm{AQ}$ ring stretch. \\
& & $v(\mathrm{C}-\mathrm{N}), v(\mathrm{~N}=\mathrm{N})$ \\
$200-210$ & $1600-1700$ & $\mathrm{AQ}$ aromatic def. \\
& & $v(\mathrm{C}=\mathrm{C}), v(\mathrm{C}=\mathrm{O})$ \\
$230-235$ & $1850-1890$ & $\delta(=\mathrm{C}-\mathrm{H})$ overtones \\
$250-265$ & $2015-2140$ & $\delta(=\mathrm{C}-\mathrm{H})$ overtones \\
$285-310$ & $2300-2500$ & $v(\mathrm{~N} \equiv \mathrm{N})$ \\
$345-360$ & $2780-2900$ & $v(\mathrm{C}=\mathrm{C})$ overtones \\
& & $v\left(\mathrm{CH} \mathrm{H}_{2}\right)$ \\
$400-415$ & $3225-3350$ & $v(\mathrm{~N}-\mathrm{H}), v(\mathrm{O}-\mathrm{H})$ \\
& & $v(\mathrm{C}=\mathrm{O})$ overtones \\
$427-450$ & $3440-3630$ & $v(\mathrm{C}=\mathrm{C})$ overtones \\
& & $v(\mathrm{O}-\mathrm{H})$ \\
\hline \hline & &
\end{tabular}

form of anthraquinone. Results of the peaks assignment are summarized in Table I.

In order to confirm that the origin of the measured structures is related to el-ph interaction, we have analyzed in more details the peak measured at $\mathrm{V}=-35 \mathrm{mV}$ in Fig. 1(c) attributed to the $\mathrm{Au}-\mathrm{N}$ bond and obviously correlated to the electronic transport within the layer. Typically in IETS, the position, width, and intensity of the peaks contain information about the underlying process during the el-ph interaction [55-62]. It is well established that the peaks width of the $d^{2} I / d V^{2}$ spectra is related to an intrinsic linewidth associated to the molecular structure $\left(W_{i}\right)$ and broadening effects associated to the experimental conditions (thermal broadening and instrumental broadening) [58-62]. The full expression of the full width at half maximum (FWHM) expected for IETS peaks is driven by these contributions [58-62]:

$$
\mathrm{FWHM}=\sqrt{\left(1.7 V_{\mathrm{ac}}\right)^{2}+\left(5.44 \frac{k_{B} T}{e}\right)^{2}+W_{i}^{2}},
$$

where $V_{\mathrm{ac}}$ is the root mean square (rms) amplitude of the ac modulation signal, $k_{B}$ the Boltzmann constant, $T$ the temperature, and $e$ the electronic charge. We have investigated the ac modulation signal dependency of the FWHM for the peak measured at $V=-35 \mathrm{mV}$ in Fig. 1(c), while fixing the temperature at $5 \mathrm{~K}$ as shown in Fig. 3 (black points). The continuous red curve in Fig. 3 represents the fit of the experimental data following Eq. (1), where the only free parameter is the intrinsic broadening $W_{i}$. The fit follows remarkably well the experimental data. The extracted value of the intrinsic broadening is equal to $W_{i}=4.2 \pm 0.4 \mathrm{meV}$, which in wave number units corresponds to $\sim 30 \mathrm{~cm}^{-1}$, in 


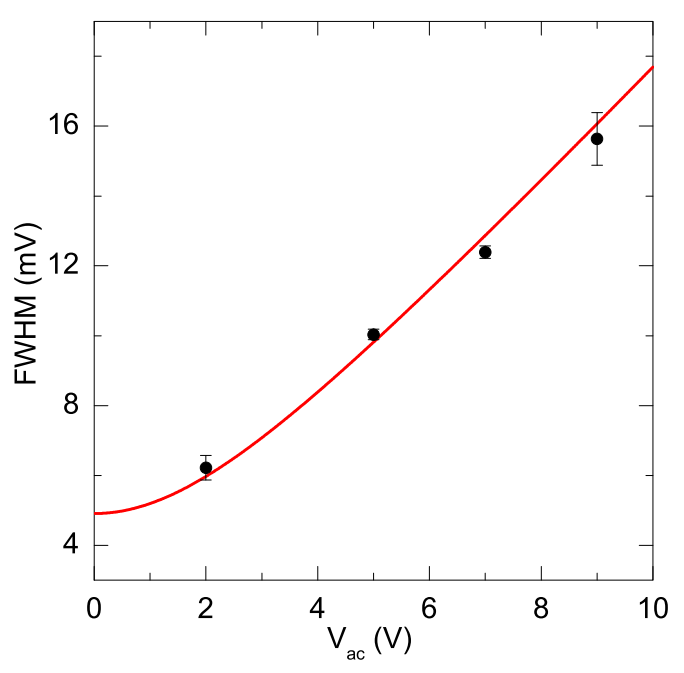

FIG. 3. FWHM as function of the rms ac voltage (black points) for the resonant peak measured at $V=-35 \mathrm{mV}$ in Fig. 1(c). The continuous red curve represents the fit of the experimental data following Eq. (1).

agreement with typical intrinsic peak broadening estimated by optical spectroscopy investigations [42]. As an important result, such analysis confirms that the considered peak in the $d^{2} I / d V^{2}$ curves results from an intrinsic vibrational mode of the molecular layer forming the junction.

\section{COMPARISON TO AQ LAYER INFRARED SPECTROSCOPY}

The investigation of a thin layer of AQ molecules by infrared spectroscopy is now presented. We show in Fig. 4(a) the IR ATR spectra on an AQ grafted gold surface in the same energy range explored for transport measurements. The spectra is normalized to a reference acquired in the same experimental

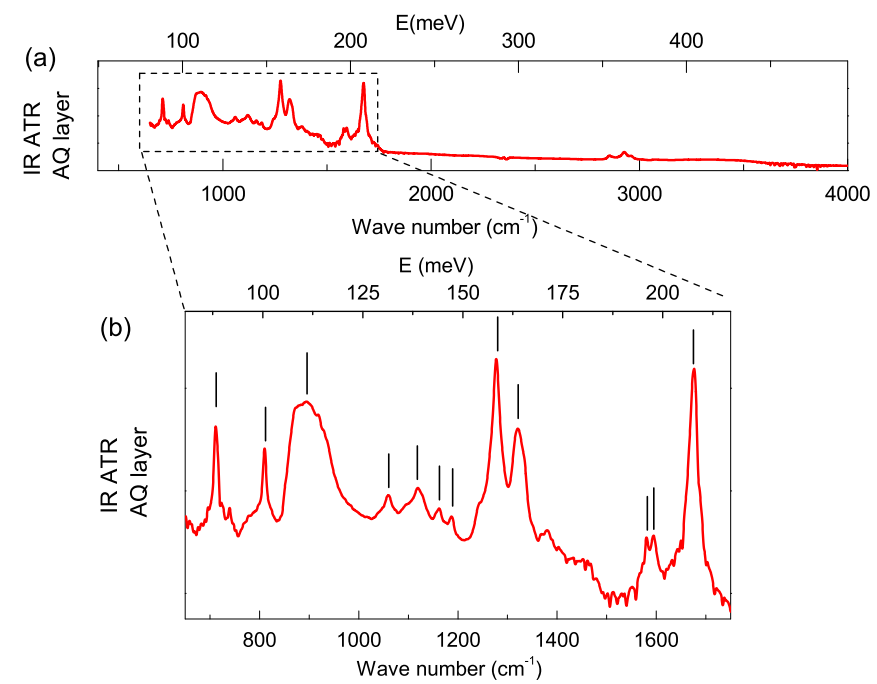

FIG. 4. (a) IR ATR spectra on the AQ grafted gold surface. Information about el-ph excited modes are associated to peaks. (b) Zoom of the spectra in the low energy region. Most evident vibrational bands are indicated by vertical black lines.
TABLE II. Assignment of main vibrational modes identified in Fig. 4 by IR ATR spectroscopy.

\begin{tabular}{lcc}
\hline \hline $\begin{array}{l}\text { Energy } \\
(\mathrm{meV})\end{array}$ & $\begin{array}{c}\text { Wave number } \\
\left(\mathrm{cm}^{-1}\right)\end{array}$ & Assignment \\
\hline 88 & 710 & $\delta_{\text {oop }}(=\mathrm{C}-\mathrm{H})$ \\
100 & 810 & $\delta_{\text {oop }}(=\mathrm{C}-\mathrm{H})$ \\
& $\delta(\mathrm{N}-\mathrm{H})$ \\
$107-115$ & $860-930$ & $\delta_{\text {oop }}(=\mathrm{C}-\mathrm{H})$ \\
130 & 1060 & $\delta_{i p}(=\mathrm{C}-\mathrm{H})$ \\
& & $v(\mathrm{C}-\mathrm{C})$ \\
140 & 1120 & $\delta(=\mathrm{C}-\mathrm{H})$ \\
147 & 1190 & $v(\mathrm{C}-\mathrm{C})$ \\
159 & 1280 & $\delta(=\mathrm{C}-\mathrm{H})$ \\
164 & 1320 & $\mathrm{AQ}$ ring stretch. \\
& & $v(\mathrm{C}-\mathrm{N}), v(\mathrm{~N}=\mathrm{N})$ \\
$196-198$ & $1580-1600$ & $\mathrm{AQ}$ aromatic def. \\
& & $v(\mathrm{C}=\mathrm{C}), v(\mathrm{C}=\mathrm{O})$ \\
208 & 1675 & $\mathrm{AQ}$ aromatic def. \\
& & $v(\mathrm{C}=\mathrm{C}), v(\mathrm{C}=\mathrm{O})$ \\
\hline \hline
\end{tabular}

conditions on a clean Au surface. Information about the excited modes is associated to peaks in the curve.

It is worthwhile to note that IR spectroscopy is lacking in reliable vibrational signatures in the higher $(200<V<$ $500 \mathrm{meV})$ as well as the lower $(V<80 \mathrm{meV})$ spectral energy range, whereas IETS is able to produce clear information. In the high energy range are only visible structures at 355-365 meV (2860-2960 $\left.\mathrm{cm}^{-1}\right)$ that can be related to $\mathrm{CH}_{2}$ stretching of residual $\mathrm{C}_{2} \mathrm{H}_{3} \mathrm{~N}$ solvent [42]. Figure 4(b) shows the same spectra in the region $80<V<210 \mathrm{meV}$ $\left(645-1690 \mathrm{~cm}^{-1}\right)$, where most of the peaks are detected. Most evident vibrational bands are highlighted by black vertical lines. Their assignment is done following the literature $[21,34,35,42-54]$ and is summarized in Table II.

While IETS is typically difficult to interpret since there are no strict theoretical determined selection rules and propensity rules have only been proposed [63,64], in IR spectroscopy selection rules exist, simplifying the assignment of the vibrational modes. By comparing Tables I and II common modes between IETS and IR spectra can be recognized in the energy range $100 \mathrm{meV}<E<200 \mathrm{meV}$. In particular, we find common signatures of the $=\mathrm{C}-\mathrm{H}$ in-plane and outof-plane deformations in the energy range $100-130 \mathrm{meV}$ $\left(890-1050 \mathrm{~cm}^{-1}\right)[34,35,42,43,46-48]$, where signatures of the $\mathrm{N}-\mathrm{H}$ deformation or $\mathrm{C}-\mathrm{C}$ stretching are also predicted $[21,37,42,48,49]$. Common signatures of the stretching of different carbon based bonds are also detectable, such as $\mathrm{C}-\mathrm{N}, \mathrm{C}=\mathrm{C}$, and $\mathrm{C}=\mathrm{O}$ in the energy range $160-210 \mathrm{meV}$ $\left(1290-1690 \mathrm{~cm}^{-1}\right)[21,35,42,43,47-49]$. This crossed analysis shows that IETS combined with the QI effect allows one to highlight modes equivalent to what was found by optical spectroscopy. Besides that, IETS investigation clearly unveils new information in an energy range where infrared spectroscopy is lacking in signatures. The capability of IETS spectra coupled to QI to exalt the presence of peaks in the lower part of the explored energy range in fact allows one to recognize nitrogen based vibrations mostly absent in IR spectroscopy, such as $\mathrm{C}-\mathrm{N}$ stretching, $\mathrm{C}-\mathrm{N}=\mathrm{N}$ deformation, and $\mathrm{Au}-\mathrm{N}$ stretching, 
as well as a low energy mode specific to the AQ molecule. Moreover, nitrogen based modes such as $\mathrm{N} \equiv \mathrm{N}$ stretching and $\mathrm{N}-\mathrm{H}$ stretching in the higher part of the explored energy range are also exclusively revealed by IETS. Finally, IETS spectra allows one to reveal probable signatures of overtones corresponding to dominant $\mathrm{C}=\mathrm{C}, \mathrm{C}=\mathrm{O}$, and $=\mathrm{C}-\mathrm{H}$ modes, typically expected in the presence of QI. Anyway, collective modes probably occurring in molecular chains play surely an important role. More detailed theoretical simulations are necessary to investigate this aspect.

\section{CONCLUSION}

In conclusion, a joined investigation of vibrational modes of anthraquinone thin molecular layers by transport and infrared spectroscopy has been performed. An anthraquinone thin film is embedded between two metallic electrodes realizing molecular junctions that show a strong conductance reduction around zero-bias voltage, attributable to destructive quantum interference. Molecular quantum interference results from a coherent effect and is able to improve signature of inelastic electron tunneling spectroscopy, revealing characteristic vibrational modes with increased resolution particularly in the low energy range. The assignment of several vibrational mode characteristics of aromatic compounds has been performed. Infrared spectroscopy on thin anthraquinone layers allows one to reveal common modes to transport spectra. In an energy range where infrared spectroscopy is lacking, inelastic electron tunneling spectroscopy highlights information on additional existing vibrational modes. As an important result, $\mathrm{N} \equiv \mathrm{N}$ and $\mathrm{Au}-\mathrm{N}$ vibrations, hardly seen in infrared spectroscopy, are clearly evidenced in transport measurements. Destructive quantum interference-improved inelastic electron tunneling spectroscopy is affirmed thus as a powerful tool for molecular vibration detection techniques.

\section{ACKNOWLEDGMENTS}

This work is supported by the Agence Nationale de la Recherche (ANR) (Project Remind, Grant No. ANR15-CE09-0001). Commissariat Général à l'Investissement d'avenir (CGI) and ANR are acknowledged for their financial support to Labex SEAM. We acknowledge C. Manquest, P. Filloux, and S. Suffit for technical supports within the cleanroom of the Laboratoire Matériaux et Phénomènes Quantiques (UMR 7162) at the University Paris Diderot.
[1] D. M. Cardamone, C. A. Stafford, and S. Mazumdar, Nano Lett. 6, 2422 (2006).

[2] R. Baer and D. Neuhauser, J. Am. Chem. Soc. 124, 4200 (2002).

[3] R. Stadler, S. Ami, C. Joachim, and M. Forshaw, Nanotechnology 15, S115 (2004).

[4] G. C. Solomon, D. Q. Andrews, T. Hansen, R. H. Goldsmith, M. R. Wasielewski, R. P. Van Duyne, and M. A. Ratner, J. Chem. Phys. 129, 054701 (2008).

[5] D. Darau, G. Begemann, A. Donarini, and M. Grifoni, Phys. Rev. B 79, 235404 (2009).

[6] G. C. Solomon, D. Q. Andrews, R. H. Goldsmith, T. Hansen, M. R. Wasielewski, R. P. VanDuyne, and M. A. Ratner, J. Am. Chem. Soc. 130, 17301 (2008).

[7] G. C. Solomon, D. Q. Andrews, R. H. Goldsmith, T. Hansen, M. R. Wasielewski, R. P. VanDuyne, and M. A. Ratner, J. Phys. Chem. C 112, 16991 (2008).

[8] C. M. Guédon, H. Valkenier, T. Markussen, K. S. Thygesen, J. C. Hummelen, and S. J. van der Molen, Nat. Nanotechnol. 7, 305 (2012).

[9] D. Fracasso, H. Valkenier, J. C. Hummelen, G. C. Solomon, and R. Chiechi, J. Am. Chem. Soc. 133, 9556 (2011).

[10] C. R. Arroyo, S. Tarkuc, R. Frisenda, J. S. Seldenthuis, C. H. M. Woerde, R. Eelkema, F. C. Grozema, and H. S. J. van der Zant, Angew. Chem. Int. Ed. 52, 3152 (2013).

[11] V. Rabache, J. Chaste, P. Petit, M. L. Della Rocca, P. Martin, J.-C. Lacroix, R. L. McCreery, and P. Lafarge, J. Am. Chem. Soc. 135, 10218 (2013).

[12] J. P. Bergfield, M. A. Solis, and C. A. Stafford, ACS Nano 4, 5314 (2010).

[13] J. P. Berfield and C. A. Stafford, Nano Lett. 9, 3072 (2009).

[14] H. Park, J. Park, A. K. L. Lim, E. H. Anderson, A. P. Alivisatos, and P. L. McEuen, Nature (London) 407, 57 (2000).
[15] J. Park, A. N. Pasupathy, J. I. Goldsmith, C. Chang, Y. Yaish, J. R. Petta, M. Rinkoski, J. P. Sethna, H. D. Abruña, P. L. McEuen, and D. C. Ralph, Nature (London) 417, 722 (2002).

[16] L. H. Yu and D. Natelson, Nano Lett. 4, 79 (2004).

[17] L. H. Yu, Z. K. Keane, J. W. Ciszek, L. Cheng, M. P. Stewart, J. M. Tour, and D. Natelson, Phys. Rev. Lett. 93, 266802 (2004).

[18] A. R. Champagne, A. N. Pasupathy, and D. C. Ralph, Nano Lett. 5, 305 (2005).

[19] H. B. Heersche, Z. de Groot, J. A. Folk, H. S. J. van der Zant, C. Romeike, M. R. Wegewijs, L. Zobbi, D. Barreca, E. Tondello, and A. Cornia, Phys. Rev. Lett. 96, 206801 (2006).

[20] M. A. Reed, Mater. Today 11, 46 (2008).

[21] J. G. Kushmerick, J. Lazorcik, C. H. Patterson, and R. Shashidhar, Nano Lett. 4, 639 (2004).

[22] H. Song, Y. Kim, Y. H. Jang, H. Jeong, M. A. Reed, and T. Lee, Nature (London) 462, 1039 (2009).

[23] W. Wang, T. Lee, I. Kretzschmar, and M. A. Reed, Nano Lett. 4, 643 (2004).

[24] N. A. Pradhan, N. Liu, and W. Ho, J. Phys. Chem. B 109, 8513 (2005).

[25] J. Hihath, C. Bruot, and N. Tao, ACS Nano 4, 3823 (2010).

[26] C. Bruot, J. Hihath, and N. Tao, Nat. Nanotechnol. 7, 35 (2012).

[27] O. Tal, M. Krieger, B. Leerink, and J. M. van Ruitenbeek, Phys. Rev. Lett. 100, 196804 (2008).

[28] T. Markussen and K. S. Thygesen, Phys. Rev. B 89, 085420 (2014).

[29] J. Lykkebo, A. Gagliardi, A. Pecchia, and G. C. Solomon, J. Chem. Phys. 141, 124119 (2014).

[30] J. Lykkebo, A. Gagliardi, A. Pecchia, and G. C. Solomon, ACS Nano 7, 9183 (2013).

[31] P. Martin, M. L. Della Rocca, P. Lafarge, and J.-C. Lacroix, J. Am. Chem. Soc. 134, 154 (2012). 
[32] A. Bousquet, M. Ceccato, M. Hinge, S. U. Pedersen, and K. Daasbjerg, Langmuir 28, 1267 (2012).

[33] A. Mesnage, X. Lefèvre, P. Jégou, G. Deniau, and S. Palacin, Langmuir 28, 11767 (2012).

[34] L. Laurentius, S. R. Stoyanov, S. Gusarov, A. Kovalenko, R. Du, G. P. Lopinski, and M. T. McDermott, ACS Nano 5, 4219 (2011).

[35] R. Ahmad, L. Boubekeur-Lecaque, M. Nguyen, S. Lau-Truong, A. Lamouri, P. Decorse, A. Galtayries, J. Pinson, N. Felidj, and C. Mangeney, J. Chem. Phys. C 118, 19098 (2014).

[36] C. Bessis, M. L. Della Rocca, C. Barraud, P. Martin, J.-C. Lacroix, T. Markussen, and P. Lafarge, Sci. Rep. 6, 20899 (2016).

[37] Y. Kim, H. Song, F. Strigl, H. F. Pernau, T. Lee, and E. Scheer, Phys. Rev. Lett. 106, 196804 (2011).

[38] J. M. Beebe, H. J. Moore, T. R. Lee, and J. G. Kushmerick, Nano Lett. 7, 1364 (2007).

[39] R. C. Jaklevic and J. Lambe, Phys. Rev. Lett. 17, 1139 (1966).

[40] J. Klein, A. Léger, M. Belin, D. Défourneau, and M. J. L. Sangster, Phys. Rev. B 7, 2336 (1973).

[41] M. Galperin, M. A. Ratner, and A. Nitzan, J. Chem. Phys. 121, 11965 (2004).

[42] G. Socrates, Infrared and Raman Characteristic Group Frequencies: Tables and Charts (John Wiley \& Sons, New York, 2004).

[43] C. Pecile and B. Lunelli, J. Chem. Phys. 46, 2109 (1967).

[44] K. K. Lehmann, J. Smolarek, O. S. Khalil, and L. Goodman, J. Phys. Chem. 83, 1200 (1979).

[45] L. Vitali, S. D. Borisova, G. G. Rusina, E. V. Chulkov, and K. Kern, Phys. Rev. B 81, 153409 (2010).

[46] J. Clarkson and W. E. Smith, J. Mol. Struct. 655, 413 (2003).

[47] M. A. Karimi, S. G. Bahoosh, M. Herz, R. Hayakawa, F. Pauly, and E. Scheer, Nano Lett. 16, 1803 (2016).
[48] S. Betelu, I. Tijunelyte, L. Boubekeur-Lecaque, I. Ignatiadis, J. Ibrahim, S. Gaboreau, C. Berho, T. Toury, E. Guenin, N. Lidgi-Guigui, N. Felidj, E. Rinnert, and M. L. de la Chapelle, J. Phys. Chem. C 120, 18158 (2016).

[49] D. P. Long, J. L. Lazorcik, B. A. Mantooth, M. H. Moore, M. A. Ratner, A. Troisi, Y. Yao, J. W. Ciszek, J. M. Tours, and R. Shashidhar, Nat. Mater. 5, 901 (2006).

[50] A. M. Ricci, L. P. Méndez de Leo, F. J. Williams, and E. J. Calvo, Chem. Phys. Chem. 13, 2119 (2012).

[51] I. I. Rzeźnicka, H. Horino, N. Kikkawa, S. Sakaguchi, A. Morita, S. Takahashi, T. Komeda, H. Fukumura, T. Yamada, and M. Kawai, Surf. Sci. 617, 1 (2013).

[52] D. Y. Wu, M. Hayashi, Y. J. Shiu, K. K. Liang, C. H. Chang, Y. L. Yeh, and S. H. Lin, J. Phys. Chem. A 107, 9658 (2003).

[53] J. F. Li, Y. F. Huang, Y. Ding, S. B. Li, Z. L. Yang, X. S. Zhou, F. R. Fan, W. Zhang, Z. Y. Zhou, D. Y. Wu, B. Ren, Z. L. Wang, and Z. Q. Tian, Nature (London) 464, 392 (2010).

[54] P. Gao and M. J. Weaver, J. Phys. Chem. 90, 4057 (1986).

[55] D. J. Scalapino and S. M. Marcus, Phys. Rev. Lett. 18, 459 (1967).

[56] J. Kirtley, D. J. Scalapino, and P. K. Hansma, Phys. Rev. B 14, 3177 (1976).

[57] M. Galperin, M. A. Ratner, and A. Nitzan, Nano Lett. 4, 1605 (2004).

[58] E. L. Wolf, Principles of Electron Tunneling Spectroscopy (Oxford University Press, Oxford, 1985).

[59] J. Lambe and R. C. Jaklevic, Phys. Rev. 165, 821 (1968).

[60] P. K. Hansma, Phys. Rep. 30, 145 (1977).

[61] M. Paulsson, T. Frederiksen, and M. Brandbyge, Phys. Rev. B 72, 201101 (2005).

[62] T. Frederiksen, M. Paulsson, M. Brandbyge, and A.-P. Jauho, Phys. Rev. B 75, 205413 (2007).

[63] N. Lorente, M. Persson, L. J. Lauhon, and W. Ho, Phys. Rev. Lett. 86, 2593 (2001).

[64] A. Troisi and M. A. Ratner, J. Chem. Phys. 125, 214709 (2006). 